\title{
Microcalorimeter: Design Considerations, Materials and Examples
}

\author{
M. K. Khaw, F. Mohd-Yasin* and N. T. Nguyen \\ Queensland Micro- and Nanotechnology Centre, Griffith University, Nathan, 4111, Australia
}

\begin{abstract}
This review paper first discusses the design considerations that are being applied in the development of a highly sensitive, miniaturised and high throughput assay microcalorimeter. Major factors include reaction chamber, thermal insulation, fluid handling, mixing techniques and temperature sensing. Miniaturisation is the key to handle smaller sample volume within the nanoliter to picoliter regions, which is made possible by advancement in materials and fabrication technologies. Materials under review include silicon, silicon nitride, parylene-C, PMMA, PDMS, SU-8 and polymide. The materials are compared in terms of size, cost, biocompatibility, chemical resistance and thermal properties. Finally, we compile the list of works across the globe and their contributions that demonstrated microcalorimeter prototypes with high thermal insulation, precise microfluidic handling capabilities, rapid mixing of fluids and high throughputs. This review offers broad perspectives and insights for those working on microcalorimeter, enthalpy arrays, microfluidic biosensor, thermal sensor and micromixer.
\end{abstract}

Keywords: calorimeter, microcalorimeter, thermal sensor, enthalpy array, bio sensor

\section{Introduction}

Calorimetry is an analytical science for determining the changes in heat of a system with its surroundings. Calorimeter devices measure the quantity of heat transferred to or from an object. It is an essential tool to characterise the thermodynamics of chemical reactions of a sample. A microcalorimeter is a miniaturized calorimeter, which makes possible the detection of the temperature changes of a small sample volume in the order of nanoliters $(\mathrm{nL})$ down to picoliters $(\mathrm{pL})$ regions. In order to take advantage of this capability, researchers normally employ an array of microcalorimeters, which consists of a number of parallel microcalorimeters. This system promises benefits such as high-throughput measurement, portability and low power consumption [1,2].

\footnotetext{
* Corresponding author. E-mail address: f.mohd-yasin@griffith.edu.au.
} 
One potential usage will be in the pharmaceutical industry, where an array of microcalorimeters can be used in the early stages of the small molecule drug discovery process, also known as the fragment-based drug discovery (FBDD). The detailed thermodynamic characterization is needed to screen drug candidates. A microcalorimeter can determine whether the process heat from the binding interactions between the small molecule (drug candidate) and the target proteins (disease) corresponds with assumed metabolic pathways. Detection of unknown reactions is also possible. Such system is sometimes referred to as an enthalphy array. It has potential to test tens of thousands of chemical compounds, while significantly shorten the screening time. Another advantage is in term of cost. Biological samples could be very expensive and are often not available or reproducible in large quantities [1,2]. One prototype of an enthalphy array is presented in section four of this review.

Calorimetric measurement can be categorised in term of temperature change (adiabatic or isoperibol), power compensation (isothermal) and heat conduction. The temperature-change microcalorimeter is the most direct way of measuring heat. The temperature sensor records the heat released (or absorbed) by the chemical reaction of the samples in the reaction chamber. The recorded calorimetric signal is the temperature of the reaction chamber as a function of time. With an appropriate electrical or chemical calibration, the energy equivalent to the reaction chamber can be determined. The measured temperature change is converted to a heat change by multiplying the energy equivalent of the microcalorimeter (in $\mathrm{cal} / \mathrm{K}$ ) with the measured temperature change (in K) [3].

In a power compensation microcalorimeter, a heater controller keeps the temperature of the reaction chamber constant at all times. When a chemical reaction occurs in the microcalorimeter, the heater controller senses the temperature difference and applies power to regulate the chamber back to the initial temperature. The recorded power change $(\mu \mathrm{cal} / \mathrm{sec})$ is stored as a function of time. The heat change is calculated by integrating the power change of the heater over the time of measurement.

In a heat conduction microcalorimeter, a controlled heat sink keeps the reaction chamber at a constant temperature. The heat sink is coupled to the heat flow sensors. When the temperature changes due to a chemical reaction, the heat flow sensors will generate a voltage that is proportional to the temperature change.

This review paper focusses on the evolution and state-of-the-art designs, materials and technology of miniaturised and high-throughput microcalorimeters. The design considerations are discussed in section two. Some challenges and concerns are addressed. Several mixing and merging methods are also reviewed. The third section highlights the materials that are utilised in the microcalorimeter's design. These include silicon (Si), silicon nitride $\left(\mathrm{Si}_{3} \mathrm{~N}_{4}\right)$, parylene-C, Polymethyl methacrylate (PMMA), polydimethylsiloxane (PDMS), SU-8 and polyimide. Comparison of materials in terms of mechanical stability, biocompatibility with the biochemical samples, chemical resistance and thermal properties of material are also discussed. Section four compiles the list of microcalorimeter prototypes and highlights several examples that produce an excellent thermal insulation, an efficient microfluidic handling capabilities, a rapid mixing of fluids and a high throughput. 


\section{Design Considerations}

Five major components should be considered for the design of a microcalorimeter: reaction chamber, thermal insulation, fluid handling including mixing techniques, and temperature sensing. These components can be integrated in a single prototype.

\subsection{Reaction chamber}

A microcalorimeter is built on a membrane as the main structural and thermally insulating component (Figure 1). The choice of material for the membrane is often a thin film with low heat capacitance. A silicon or stainless steel rim supports the membrane. For temperature sensing, the thermometer is embedded within the membrane and is placed beneath the reaction chamber. The samples are delivered and mixed in the reaction chamber.

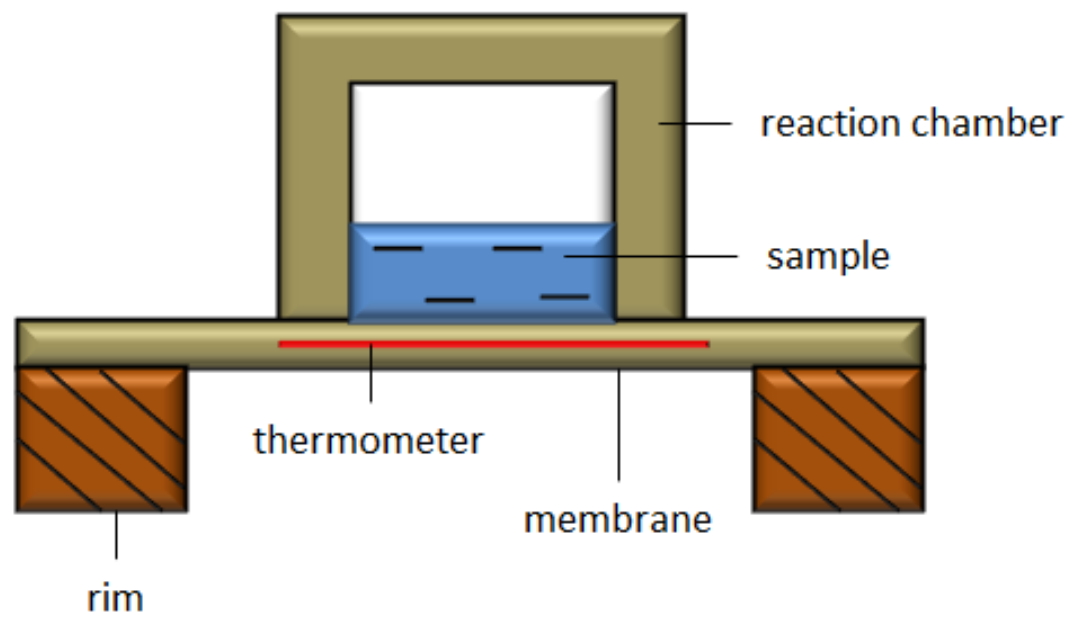

Figure 1: An illustration of a generic microcalorimeter [4]

The reaction chamber can be classified into two categories; open chamber [5-10] and closed chamber [11-17] as shown in Figure 2. The key difference is the method of fluid transfer. In the open chamber configuration, droplets of sample are directly delivered into the chamber via a micropipette or inkjet. In the closed chamber configuration, microfluidic channels are built-in to deliver the fluid sample. Conventional microfluidic channels are often bulky and are used to encapsulate the reaction chamber. Polymer thin film microfluidic channels are micromachined with the reaction chamber, giving an edge to miniaturisation and better thermal isolation.

Microcalorimeter can also be characterized in term of the delivery and treatment of the samples. There are three types: batch, flow and scanning microcalorimeter. For batch or titration microcalorimeters $[8,18]$, specific amount of samples are deposited to the reaction chamber and the change in temperature is measured. Therefore, microcalorimeters based on this approach employ the open reaction chamber. They are well-suited for measuring heat of reaction for protein-ligand binding, enzymatic activities and chemical mixture. On the other hand, flow microcalorimeters [11,13-15] utilise the closed reaction chambers due to the need of microfluidic channels to deliver a continuous flow of samples. This is suited for continuous and real time monitoring of a chemical compound or heat production of living organisms. The scanning microcalorimeters, 
or better known as differential scanning calorimeter (DSC) [19-22] measure the heat capacity change of the sample through temperature scanning. In this third approach, the difference in the amount of heat required to increase the temperature of a sample and reference is measured as a function of temperature. This is important for the investigation of the internal structure or stability of samples in their original state. A DSC needs to be implemented in a closed chamber to avoid the evaporation of the sample while heating.

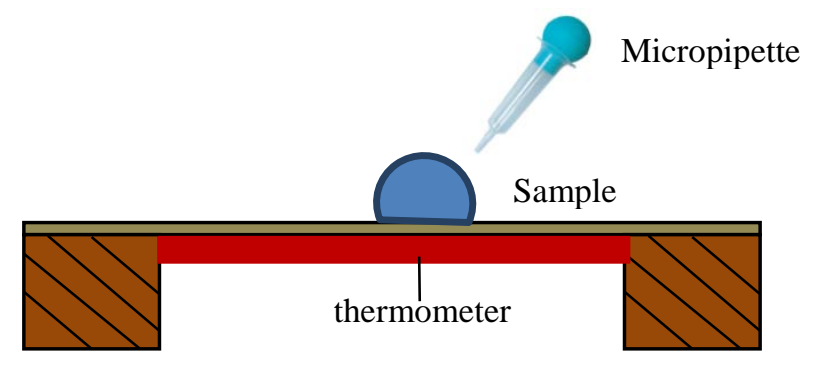

(a) Direct spotting

\section{Open chamber configuration}

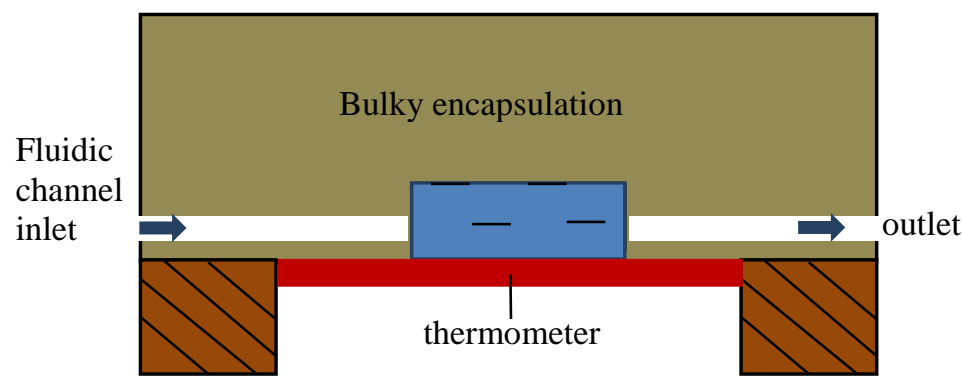

(b) Conventional microfluidic

\section{Closed chamber configuration}

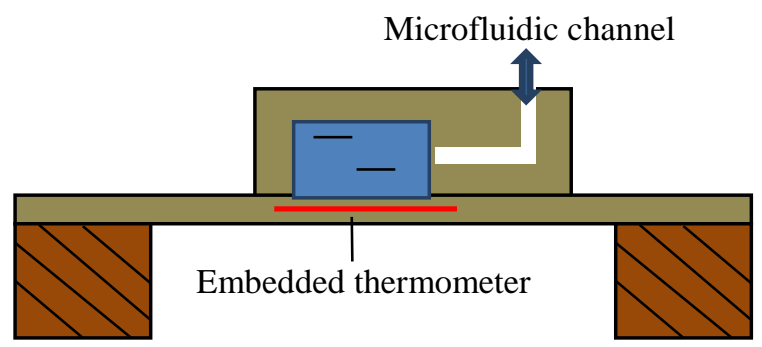

(b) Thin film microfluidic

\section{Closed chamber configuration}

Figure 2: Two types of reaction chamber; open and closed [2] 


\subsection{Thermal insulation}

Thermal insulation shields the heat of the reaction from the unwanted heat of its surroundings. In the case of a microcalorimeter, the reaction chamber is vulnerable to a substantial heat loss because of the larger surfaceto-volume ratio. Furthermore, a small volume sample produces a very small amount of heat to be measured.

The four modes of heat transfer in a reaction chamber are conduction, evaporation, convection and radiation. Conduction is the dominant mode for all microcalorimeters. The thermal conduction path for the reaction chamber includes the air, membrane and electric leads in the temperature sensor circuitry [2]. Heat loss from the sample surface to the surrounding air is the main heat transfer path for the microcalorimeter. This type of heat loss contributes to more than $90 \%$ of the total thermal conductance. One solution for minimizing the heat conduction is to incorporate a vacuum chamber. However, a vacuum is only effective for solid samples. Liquid samples in a vacuum will suffer significant mass loss due to evaporation [2]. This issue can be overcome by employing a microfluidic channel embedded in vacuum [11]. There are also microcalorimeters that incorporate the thermal shielding system [9] using low thermal conductivity materials [11,13], which include polydimethylsiloxane (PDMS), polymethylmethacrylate (PMMA), parylene-C, SU-8 and polyimide.

The choice of the material and the structural design for the membrane are important to increase the thermal insulation, and hence, the sensitivity of the device. Sensitivity in this context means the ability to measure the actual heat released from the samples excluding the thermal influence from the surroundings. The comparison of materials in terms of their thermal properties is discussed in details in Section 3. The electric lead used in some temperature sensing device, for example the Wheatstone bridge, also provides heat loss that can be eliminated by reducing the cross-section of the electric leads.

Evaporation of sample is more evident in the open chamber microcalorimeters because of the lack of physical confinement. For the closed chamber configuration, the added microfluidic structure helps to prevent evaporation. Unfortunately, microfluidic designs have larger thermal conductance to their surroundings and have greater device heat capacity compared with the open chamber configuration. Microcalorimeters with microchannels are often moulded with PDMS $[13,14]$ or etched on bulk $\mathrm{Si}$ or $\mathrm{SiO}_{2}$ substrates. The large heat capacity of the structure will absorb the heat from the small volume sample through conduction, leading to sensitivity reduction [2]. Heat loss through convection and radiation are usually not as significant as conduction and evaporation in microcalorimeters, and hence, will not be discussed in details for this review [2].

\subsection{Fluid handling}

Fluid handling involves the methods of transferring sample to the reaction chamber. For the open-chamber configuration, samples are directly supplied to the reaction chamber through micropipettes or inkjet. Sample droplets range from a few $\mu \mathrm{L}$ to hundreds of pL. Micropipettes [7-9] are commonly used, but they are relatively slower than inkjets and cannot handle multiple samples simultaneously. Inkjets [10] can deliver batch-samples and is very fast. However, the speed causes large kinetic energy onto the samples, which generate additional heat. In an open chamber configuration, the inaccuracy of the temperature measurement due to evaporation and kinetic energy of the samples often reduces the performance of the system.

For the closed-chamber configuration, samples are transported via microfluidic channels. The advancement of microfluidic technologies allows microchannels and chambers to be embedded in the membrane. The example by Lee et al. is referred [11]. Their prototype handled fluid of $700 \mathrm{pL}$ in volume with 
an accuracy of $50 \mathrm{pL}$. This was made possible by interfacing the parylene microfluidics channels on the calorimetry chip with pneumatically controlled PDMS microfluidics chip for accurate reaction control. Figure 3(a) shows the overview of the microfluidic layout of the PDMS control chip and the calorimetry chip. Figure 3(b) shows the top view of the microfluidic channel on the membrane. The PDMS control chip contained valves and peristaltic pumps (red) to pump air for pneumatic control. The PDMS flow layer (blue) containing the fluid sample was connected to the parylene channel (black) of the membrane through an SU-8 via. Injection of the sample was done by sequentially closing adjacent valves to facilitate peristaltic pumping of the fluid. Parylene, PDMS and SU-8 are polymer materials often being used in microcalorimeter, and they will be discussed in Section 3.
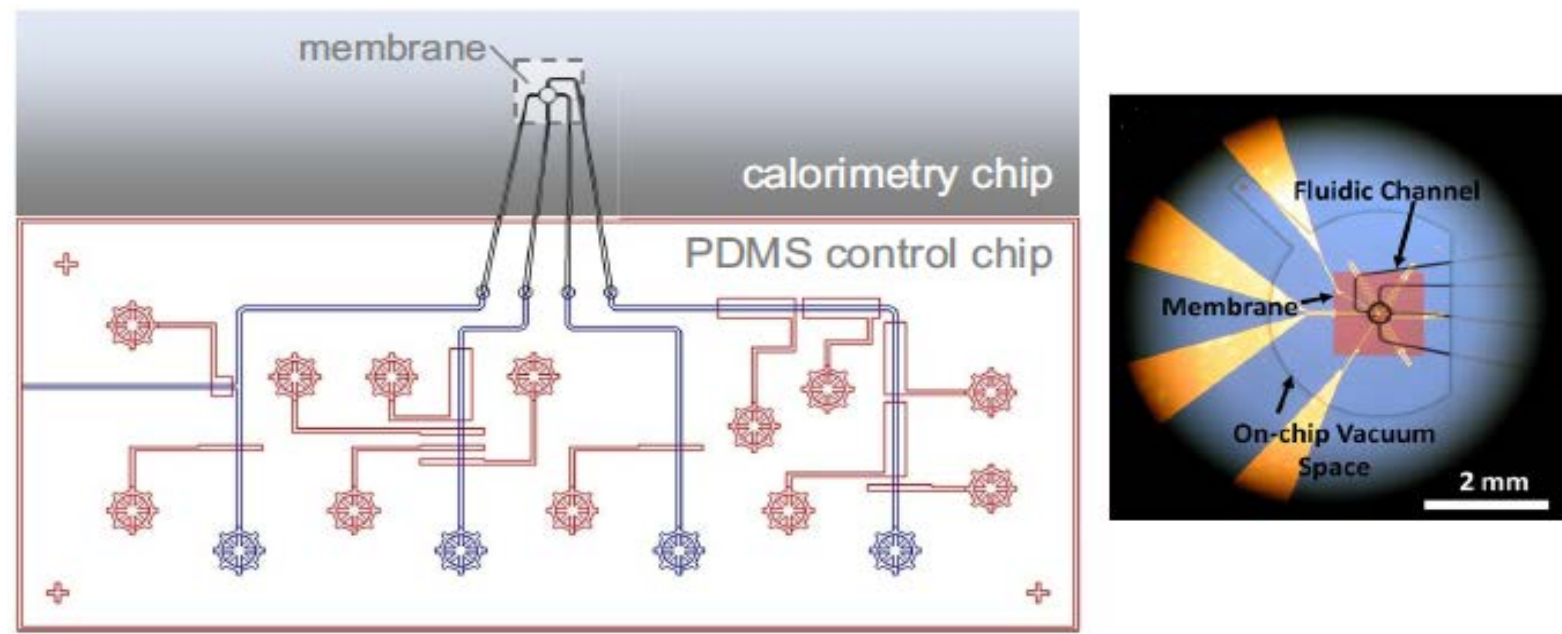

(a)

(b)

Figure 3: (a) Microfluidic layout, (b) optical microscopy image of the reaction chamber and microfluidic channel [11]

Mixing of the samples is another important consideration of fluid handling. The sample droplets should be completely mixed within a specified time frame to allow the sensitive detection of the total heat release. In other words, the duration of mixing of the droplets must be shorter than the thermal dissipation time constant of the calorimeter. Therefore, rapid mixing between the two fluids is required. There are two basic types of mixing: active and passive. Active mixing relies on the energy supplied by external sources to enhance the mixing rate, whereas passive mixing relies on improved geometric features to accomplish the same objective. Some notable active mixing include electrostatic mixing [5,6], magnet-actuated droplet mixing $[23,24]$ and magnetic micro-stirring [25,26].

\subsubsection{Electrostatically actuated droplet mixing}

Electrostatic method [5,6] employs two electrodes to mix the droplets. Droplets of different samples are separately micropipetted into the reaction chamber. When the droplets come to thermal equilibrium, the two samples merge and mix isothermally. The separation of the sample delivery and mixing can minimise heat losses during delivery. Further uncertainty can happen due to the additional heat from the kinetic energy of the samples during delivery. Figure 4 is the specific example of electrostatic mixing by Torres et al. [5]. It showed the electrostatic merging of two $500 \mathrm{~nL}$ droplets of water at three different times. Initially, the undyed droplet was placed asymmetrically across a $50 \mu \mathrm{m}$ gap (shown as a white line in the figure) between two electrodes on the device surface. A voltage of $100 \mathrm{~V}$ was applied across the gap to move the droplet until it 
covered equal amount of both electrodes. The dyed droplet was placed within the range of this motion and merged with the first droplet upon contact. $33 \mathrm{~ms}$ after applying the voltage, the droplets were merged. By 66 $\mathrm{ms}$, the final mixture was formed. The combination of the electrostatic force and the inertial force caused by the surface tension of the moving droplet provided a thorough mixing of the sample.

In order to eliminate effects of heat dilution and variations in the surroundings, a differential temperature measurement can be incorporated using adjacent reference mixing droplets. The reference droplets should be chosen to be equal in volume to the measured droplets. With this arrangement, the temperature of the samples under study is measured relative to the reference samples.

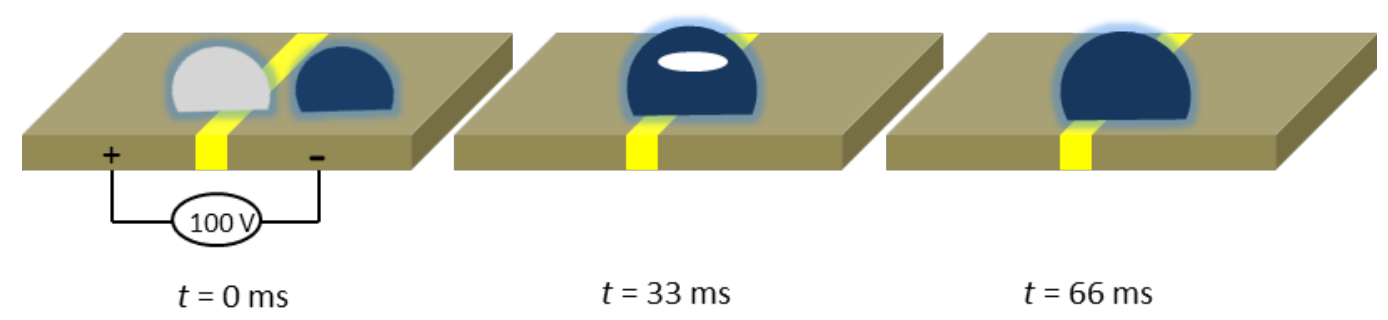

Figure 4: Electrostatic mixing and merging of two droplets [5]

\subsubsection{Magnetically actuated droplet mixing}

Magnet-actuated mixing [23,24] utilises a droplet with embedded magnetic particles for mixing. The movement of this droplet is controlled by an external magnet. Figure 5 shows an example of this mixing concept, which was performed by Long et al. [24]. The oil-coated droplet with magnetic beads was transferred onto the glass slide through precise pipetting. First, the suspended magnetic particles in the aqueous droplet were attracted to the bottom of the droplet by the magnetic force. The magnet was moved horizontally by a motorised linear stage. The particles follow the magnet until the two droplets merged. The magnet and the merged droplets were subsequently moved back and forth to mix the two liquids. 


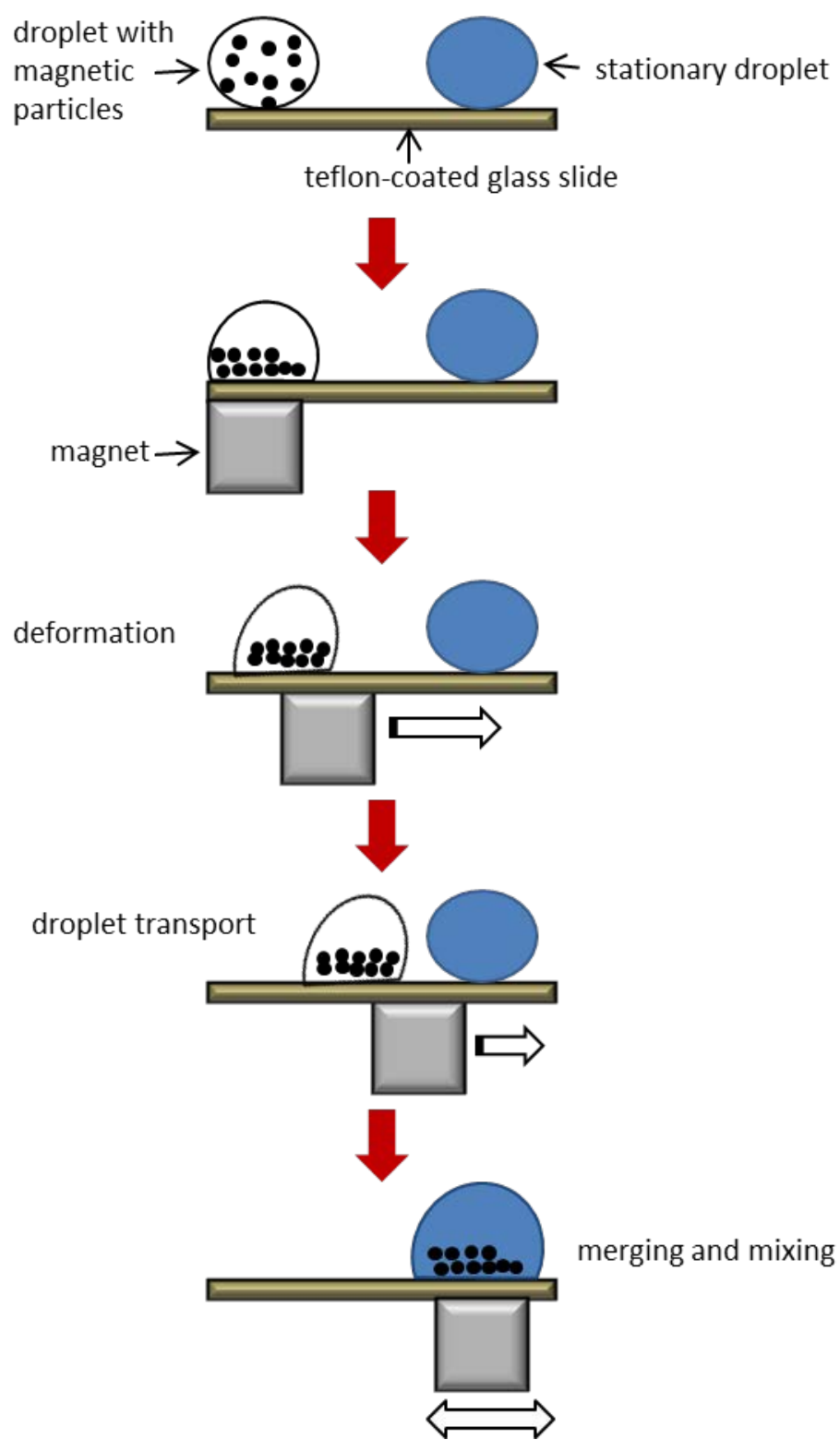

Figure 5: Magnetically-actuated mixing and merging of two droplets [24]

\subsubsection{Magnetically actuated stirring}

Magnetic micro-stirring [25,26] is a combination of electrostatic-actuated mixing and magnetic stirring. Figure 6 shows the setup of the magnetic stirring, which was performed by De Bruyker et al. [25]. The stir bar was fabricated using laser micromachining. The bar was placed on the surface of the microcalorimeter's membrane. The stir bar was remotely activated by an externally rotating magnetic field at the bottom of the 
membrane. Initially, the droplets were merged by electrostatic mixing, as discussed in Section 2.3.1. Once both droplets merged, the stir bar was activated. The axis of rotation of the magnet was centred below the stir bar to reduce unwanted lateral motion of the bar and to prevent spreading of the droplets. In this particular work, the mixing times were $1.8 \mathrm{~s}$ and $2.1 \mathrm{~s}$ with the stirring rate of $600 \mathrm{rpm}$ and $1500 \mathrm{rpm}$, respectively. It was found that the stirring rate yield minimum difference in the mixing time. However, the difference in the mixing time using magnetically-actuated stirring and using electrostatic actuated mixing was large. The mixing time was $29.5 \mathrm{~s}$ with the latter method [25].

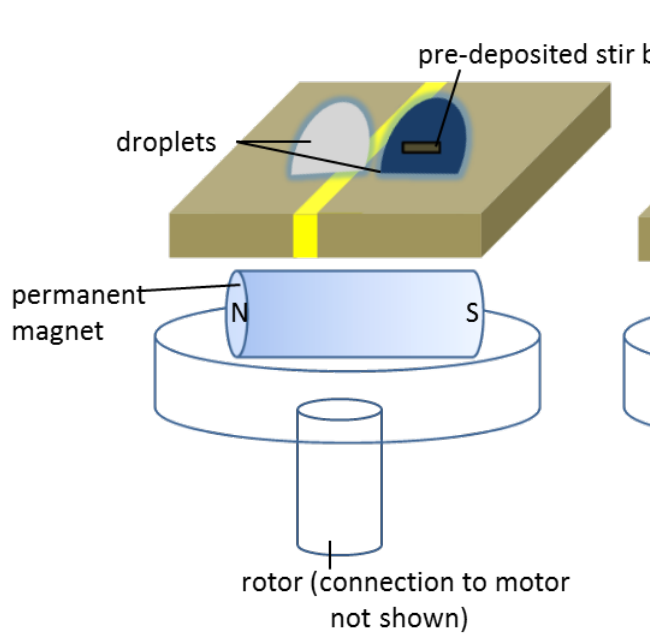

(a)

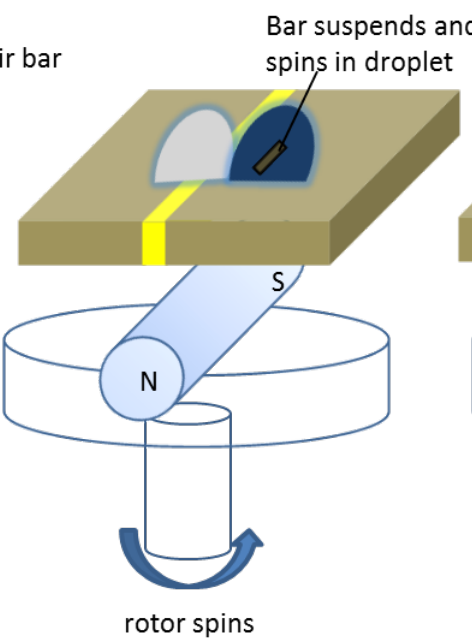

(b)
Merging voltage applied. Droplets merge and mix.

Figure 6: Magnetically- and electrostatically-actuated stirring of two droplets [25]

\subsubsection{Summary on mixing}

Mixing that is induced entirely by merging of droplets leads to a rather large mixing time because diffusive mixing dominates. However, this method is still suitable and adequate for simple measurement of the total enthalpy for some biological reactions. In order to perform the full kinetic characterization of enzymatic reactions, their droplets must be thoroughly mixed to substantially reduce the mixing time. In that case, an active mixing is preferred.

Generally, mixing methods must follow several requirements for a better accuracy:

- Mixing of the droplets must occur on a time scale shorter than the thermal dissipation time constant of the calorimeter.

- Mixing method should not give rise to a differential temperature increase of the mixed droplets, or causes differential eddy current heating in the fluids.

- Mixing method must be scalable.

- Mixing method should not affect the biochemistry and reactions of the droplets.

- Mixing method should not interfere with the temperature sensing device. 


\subsection{Temperature sensing}

Temperature sensing provides the mean for accurate temperature measurement in the reaction chamber. The sensitivity of the microcalorimeter is measured by the minimum thermal energy or power detected through the thermometer. The two common types of thermometers are thermistors and thermopiles. These thermometers are usually fabricated directly on the membrane. Three types of temperature sensor that have been implemented for microcalorimeters are discussed i.e. thermistor, thermopile and resistive-temperature detector.

Thermistors are temperature sensitive resistors that detect the change in temperature and convert to electrical resistance. The main advantage is the fact that thermistors can measure absolute temperature. Since thermistors rely on electric current to measure resistance, precautions must be taken to avoid overheating that will cause the rise of the temperature in the reaction chamber. This heating effect must be offset when calibrating the chip calorimeter. There are three notable works $[5,6,27]$ that employed thermistors in their microcalorimeters.

On the other hand, thermopiles measure temperature difference between two areas at thermocouple junctions and convert it to electric voltage. Although they can only measure relative temperature, thermopiles have higher sensitivity than thermistors because of the absence of an electrical current. Due to this factor, thermopiles have excellent common-mode thermal noise rejection ratio and zero offset. Many groups that design microcalorimeters used thermopiles in their implementation [8,10-13,15,17,28-33]. The sensitivity and the signal-to-noise ratio can be further improved by increasing the number of thermocouples connected in series. However, an array of microcalorimeters has to limit the numbers of thermocouple junctions that can be placed due to the limited size. Nevertheless, thermopiles are more suited for miniaturization compared to thermistors. Thermocouples can be formed from bimetallic microjunctions. They allow low temperature processing, which is suitable for polymer membranes. Common bimetallic microjunctions are Au-Ni [7,11], $\mathrm{Cr} / \mathrm{Ni}[15], \mathrm{Ti} / \mathrm{Bi}[10]$ and $\mathrm{Cr} / \mathrm{Cu}[32]$.

Davaji et. al [16] used a resistive temperature detector (RTD) in their microcalorimeter. RTD works on the similar principle as thermistor. The difference between RTD and thermistor is that the former uses metallic element such as platinum, nickel, copper and nickel-iron. Thermistor generally uses ceramic or semiconductor devices. The RTD temperature sensor's advantages over thermocouples are high accuracy, stability, linearity, reproducibility and ease of fabrication [16]. However, thermistors typically achieve a higher precision within a smaller range of temperature compare to RTD.

Device sensitivity indicates how precise the output is able to detect the changes when the temperature of the sample-under-test varies. In general, the sensitivity of the microcalorimeter increases when it can avoid heat loss in its reaction chamber. Also, a temperature sensor embedded into the microcalorimeter must be able to accurately measure the heat reaction by minimising unwanted noise. Several groups $[5,6,15,16,33]$ reduced the common-mode noise of their prototypes by employing a differential scheme. The temperature sensors on both the measurement and reference areas are connected in a Wheatstone bridge configuration. Using this scheme, the measured temperature change of the sample reaction was compared against the reference temperature. This method effectively cancelled out associated background drifts in temperature since the reference sample interacted with the surroundings and underwent mixing simultaneously with the sampleunder-test. 


\section{Material for microcalorimeters}

Table 1: Comparison of materials commonly used in microcalorimeters in terms of processing methods, mechanical stability, biocompatibility and chemical resistance

\begin{tabular}{|c|c|c|c|c|}
\hline Materials & Representative processing methods [34] & Mechanical stability & Biocompatibility & $\begin{array}{l}\text { Chemical } \\
\text { resistance }\end{array}$ \\
\hline $\mathrm{Si}$ & $\begin{array}{l}\text { Bulk micromachining and surface } \\
\text { micromachining }\end{array}$ & $\begin{array}{l}\text { High Young's } \\
\text { modulus but brittle }\end{array}$ & Good [35] & Excellent \\
\hline $\mathrm{Si}_{3} \mathrm{~N}_{4}$ & $\begin{array}{lll}\text { Low Pressure } & \text { Chemical } & \text { Vapour } \\
\text { Deposition (LPCVD) } & \\
\end{array}$ & $\begin{array}{l}\text { Superior resistance to } \\
\text { mechanical stress }\end{array}$ & Good [36] & Excellent \\
\hline PDMS & Replica Moulding [37] & Low Young's modulus & Excellent & $\begin{array}{l}\text { Not for organic } \\
\text { solvents }\end{array}$ \\
\hline PMMA & $\begin{array}{l}\text { Laser machining, Injection moulding, } \mathrm{x} \text { - } \\
\text { ray exposure, hot embossing }\end{array}$ & $\begin{array}{ll}\text { High } & \text { Young's } \\
\text { Modulus } & \\
\end{array}$ & Excellent & Good [38] \\
\hline Parylene-C & Chemical Vapour Deposition (CVD) & $\begin{array}{ll}\begin{array}{l}\text { High } \\
\text { strength. }\end{array} & \text { mechanical } \\
\end{array}$ & Excellent & Excellent \\
\hline SU-8 & Photolithography [39], spin coating [13] & Low Young's modulus & Excellent & Excellent \\
\hline Polyimide & Spin coating, extrusion & High tensile strength & Excellent & Excellent \\
\hline
\end{tabular}

Table 2: Thermal properties of the materials commonly used in microcalorimeters, compared with other materials. [2,40]

\begin{tabular}{|l|l|l|}
\hline Materials & Thermal conductivity (W/m.K) & Specific heat (J/g.K) \\
\hline $\mathrm{Si}$ & 130 & 0.71 \\
\hline $\mathrm{Si}_{3} \mathrm{~N}_{4}$ & $15-30$ & 0.70 \\
\hline PDMS & 0.15 & 1.46 \\
\hline PMMA & $0.19-0.24$ & $1.46-1.47$ \\
\hline Parylene-C & 0.082 & 0.71 \\
\hline SU-8 & 0.20 & 1.50 \\
\hline Polyimide & 0.12 & 1.09 \\
\hline Water & 0.58 & 4.20 \\
\hline Air & 0.026 & 1.01 \\
\hline Stainless steel, austenitic grade & $11-16$ & $0.45-0.55$ \\
\hline Gold & 315 & 0.13 \\
\hline Nickel & 90.7 & 0.44 \\
\hline
\end{tabular}

Table 1 lists the material candidates for making microcalorimeters and their processing methods, mechanical stability, biocompatibility and chemical resistance. Table 2 shows their thermal properties.

Generally, the membrane of a microcalorimeter is made of silicon ( $\mathrm{Si}$ ) or other silicon dielectric materials such as silicon nitride $\left(\mathrm{Si}_{3} \mathrm{~N}_{4}\right)$. These materials have relatively high thermal conductivities, small thicknesses (a few hundred $\mathrm{nm}$ ) and relatively good insulation. Furthermore, silicon nitride $\left(\mathrm{Si}_{3} \mathrm{~N}_{4}\right)$ has excellent mechanical properties with good corrosion and oxidation resistance. It also has good thermal stress resistance due to the low coefficient of thermal expansion.

However, in terms of thermal insulation, polymer membranes are better. The polymers that are commonly used in microcalorimeters are PDMS, PMMA, parylene-C, SU-8 and polyimide. These polymer membranes have around 100 times lower thermal conductivities and are 10 times thicker than the Si-based materials [2].

The use of polymers as the substrate materials for the microcalorimeter also originated from the need of incorporating microfluidics as an automated fluid handling component. Industries and academia working on microfluidics have long seen the potential benefits in employing polymers, mainly due to its flexibility, low 
cost per unit area and simplified manufacturing processes. Compared to silicon and glass, polymer is cheaper. For instance, a PMMA sheet of $1.5 \mathrm{~mm} \times 1.2 \mathrm{~m} \times 1.8 \mathrm{~m}$ costs about $\$ 17$, while a silicon wafer with a $100 \mathrm{~mm}$ in diameter costs $\$ 14$. The costs comparison is simplified by ignoring the cost of cutting and milling PMMA sheet into wafer shape [41]. Furthermore, the processing of certain polymers can be accomplished outside of the cleanroom, thus lowering the cost of fabrication.

Many polymer materials provide greater mechanical yield strain than silicon. Although silicon with a large Young's modulus is mechanically strong, this material is relatively brittle. Polymers can sustain greater degree of deformation and provide chemical, structural and biological functionalities, as shown in Table 1. Several types of polymers are explained next.

Parylene is a variety of chemical-vapour-deposited poly (p-xylylene) polymers. Parylene is an excellent material for the thermal insulation of the reaction chamber. Traditionally, parylene is used to form an insulating thermoplastic coating on electronic devices. Recently, this material has been used as a substrate for the membrane of a microcalorimeter [11]. Parylene-C is more often the popular choice in microcalorimeter. It can be formed into very thin and conformal layers, and has a good chemical resistance and biocompatibility, which are favourable for fluid handling [42]. The low thermal conductivity of parylene decreases the heat loss. Furthermore, parylene has very low gas permeability and high mechanical strength allowing vacuum encapsulation [11].

PDMS is a polymer consisting of inorganic siloxane backbone with methyl groups attached to the silicon [37]. It is a potential material for the fluid handling component. It has been the popular material for microfluidics [15] [11,32] due to its low cost, robustness, excellent proven biocompatibility [43], nonpermeability to liquids, optical transparency and ability to withstand very big distortions without deteriorating features. PDMS can be micromachined using replica moulding. It is best to replicate structures on the surface of the mould as it can be cast at room temperature and thermally annealed. Despite these advantages, PDMS suffers from swelling in most organic solvents. The swelling makes handling organic solvents impossible in these PDMS devices.

PMMA is a thermoplastic polymer with high mechanical strength, high chemical resistance, high Young's modulus and low elongation at break. It is one of the hardest thermoplastics, exhibits low moisture absorbing capacity and has good resistance to extreme temperature changes. PMMA can be micromachined through x-ray exposure, hot embossing, laser machining and injection moulding. In a recent comparison of mechanical behaviour of PMMA and PDMS [44], the latter is better than the former in terms of maximum deformation. In a microcalorimeter, the PMMA is normally used as the structural material for the reaction chamber and the PDMS is normally used as the microfluidic channels.

The negative thick-film photoresist SU-8 was patented by IBM in 1989 [45]. This photoresist consists of EPON Resin SU-8 (from Shell Chemicals) as a main component. SU-8 has been used as the structural material in labs-on-chip devices [46] and also in microcalorimeters [13,15]. It has good chemical compatibility and biocompatibility, and is suitable for coating conformal surfaces for protection. For instance, SU-8 was used to planarize the surfaces of the microcalorimeter with a parylene membrane [11]. The cost of SU-8 photolithography is considerably lower than other techniques such as LIGA process (for other photoresist) and the deep reactive ion etching (for silicon). 


\section{Design examples}

In this section, we highlight several microcalorimeter designs with recent breakthroughs in device performances. The key to the improvements are good thermal insulation, efficient fluid handling mechanism and clever use of materials and fabrication processes. Different reaction chamber designs (closed and open) and thermal detectors (thermopiles, thermistors and other temperature sensors) are also explored.

The researchers from Palo Alto Research Centre and the Scripps Research Institute [5,6,47,48] developed an enthalpy array. It was a microcalorimeter in an array format that allows parallel measurement of the thermodynamics parameters such as enthalpy, entropy, Gibbs free energy and stoichiometry, which promises higher throughput for FBDD screening. This enthalpy array required small sample volume in the submicrolitre and increases throughput by executing measurements in parallel. The use of micromachining technology enabled the miniaturisation of the temperature detectors, thus reducing the volume of sample significantly. Sample volume was reduced from $190 \mu$ [49] using a commercial Isothermal Titration Calorimeter (ITC) to $500 \mathrm{~nL}$ [5] of a droplet in these microcalorimeters. The system consisted of an array of individual thermal detectors, built on a thermally insulating thin plastic membrane. Figure 7 shows an individual detector and Figure 8 shows the entire array.
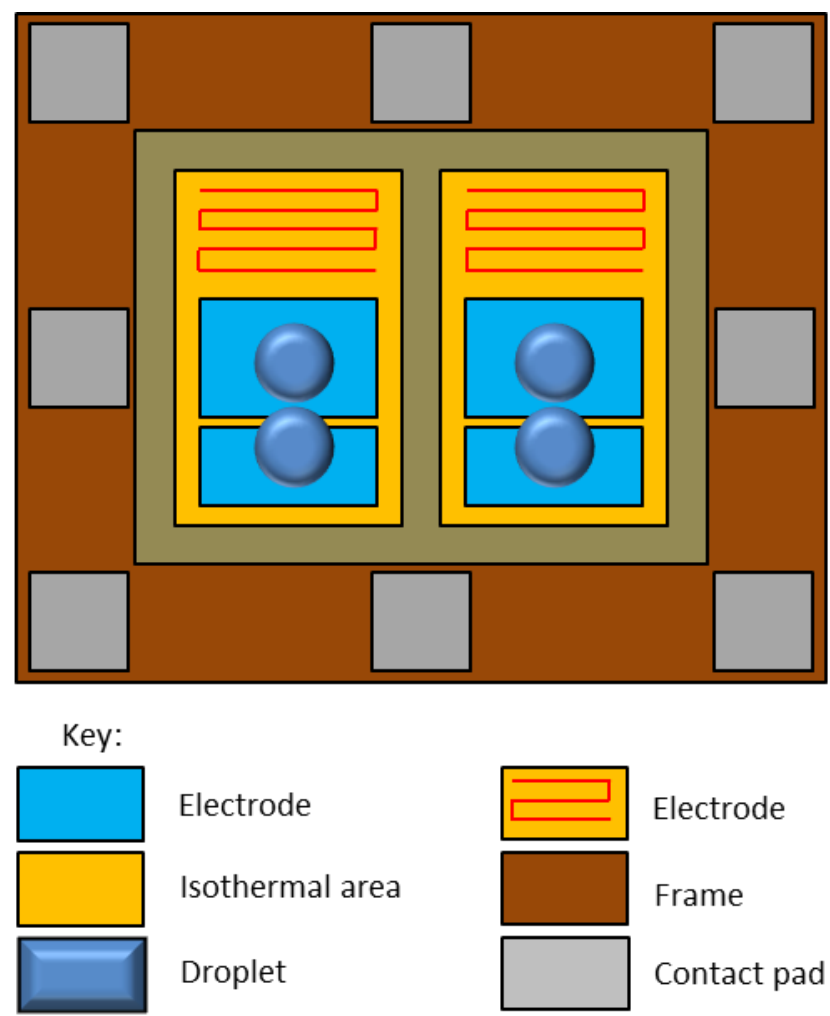

Membrane

Figure 7: Schematic view of an individual detector [5]. It has two sensing regions: the reference and the measurement chamber. Two reacting droplets are placed on the left region, and the non-reacting droplets are placed on the right region. 


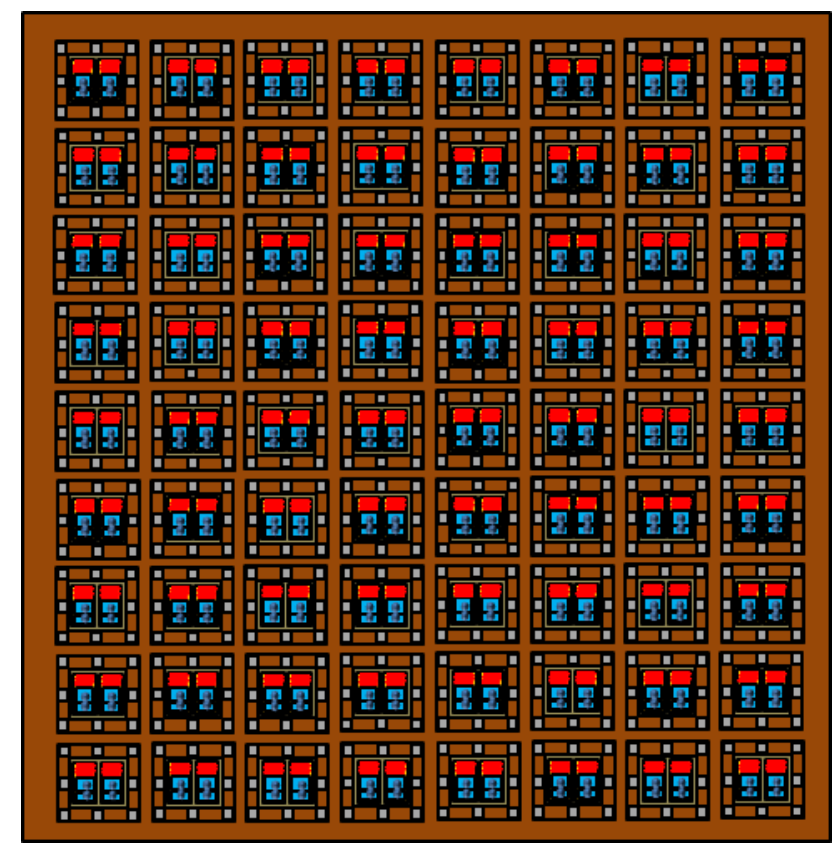

Figure 8: Enthalpy array with 72 individual detectors [48]

Each individual detector was fabricated on a thin film membrane suspended over a cavity in a rigid stainless-steel support plate. The type of membrane varied from polyimide [5] to polyethylene naphthalate (PEN) [6]. Two rectangular thermal equilibration regions consisted of $9 \mu \mathrm{m}$ thick copper islands etched on the bottom of the membrane. This design employed differential method to measure the temperature. Therefore, the device had two similar sensing regions: the reference and the measurement chamber. The sensing regions were enclosed by electrical contact pads located on top of the support plate. Each region contained two thermistors.

The thermistors in both regions were connected to a Wheatstone bridge to reduce the common-mode noise. The thermistors were fabricated from an $n+$ amorphous silicon film [5] deposited by plasma enhanced chemical vapour deposition (PECVD) using silane and phosphine. As part of thermal insulation, a polymer cap layer enclosed the array in order to minimize drop evaporation, as shown in Figure 9. Device sensitivity had improved by almost an order of magnitude when the thermistor material was changed from amorphous silicon [5] to vanadium oxide [6], and finally to the use of the cantilever microprobes [50]. 


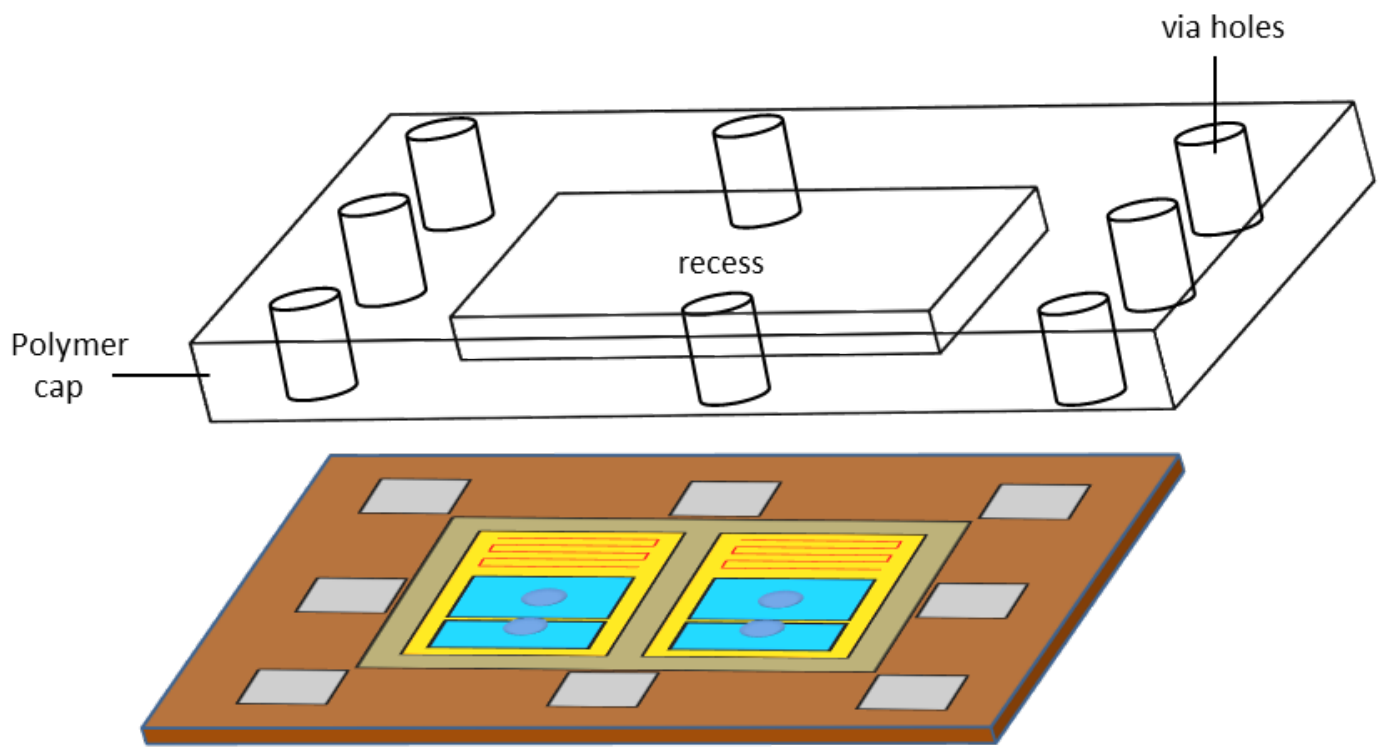

Figure 9: Schematic view of an individual detector with the polymer cap to minimize drop evaporation [6].

During measurement, two droplets of $250 \mathrm{nl}$ samples were initially merged electrostatically on the sensing region. Two identical non-reacting droplets were merged on the reference sensing region at the same time to provide a reference for the differential measurement. Upon merging, the output voltage of the Wheatstone bridge was recorded. The signal was amplified by an analogue amplifier, and then sent to a digitization and lock-in detection stage. The entire process of array manipulation, drop deposition, detector encapsulation, contacting and data recording were performed using a fully automated measurement system. With this method, any temperature rise in the sample under test will be precisely recorded. All measurements were performed at a fix temperature. The thermal dissipation time of the system was $1.3 \mathrm{~s}$. Each detector in the enthalpy array was able to detect a $500 \mu \mathrm{K}$ of temperature change with a signal-to-noise ratio of 6 [5].

Zieren et. al [14] developed the first generation of silicon microcalorimeter with integrated thermopiles. The thermopile consisted of $4 \times 118 \mathrm{BiSb} / \mathrm{Sb}$ thermocouples. The total thermopower (or Seebeck coefficient [51]) of the thermopile was $63.7 \mathrm{mV} / \mathrm{K}$. The microcalorimeter was formed by a silicon chip and a PMMA chip, which were bonded with chemically inert epoxy glue. Two layers of silicon nitride of $1 \mu \mathrm{m}$ thickness were deposited onto the silicon chip to form the free-standing membrane. Thin film of platinum and aluminium were deposited to form heaters for calibration and contact pads, respectively. The thermocouples were patterned in a way that the active junctions were located on the free-standing membrane. Reference junctions were in close contact with the silicon frame. Through this method, the membrane maximized the thermal resistance between the hot and cold junctions. The silicon also acted as a heat sink. Although this microcalorimeter achieved a rather high sensitivity, it's membrane showed chemical and mechanical instabilities.

Baier et al. [13] found the solution to improve the chemical and mechanical stabilities of the previous work by Zieren et al. Previously, silicon nitride membrane caused micro-cracks in the structure. They coated the silicon nitride membrane with thin layers of SU-8 epoxy photoresist. Coating SU-8 on the membrane stabilized the mechanical and chemical stability of the microcalorimeter. The SU-8 resist deposited on silicon 
was tested in different acids and bases ranging from a $\mathrm{pH}$ of 5-10 and showed no detectable corrosion over a period of more than 1000 hours.

Figure 10 shows the integration of dual thermopiles and a microchannel by Kwak et al. [32]. The dual thermopiles system effectively measured the heat generated by the biochemical reaction, and monitored the thermal equilibrium of the microcalorimeter in a self-compensation mode, without the need for adiabatic condition. This system was fabricated with chromium $(\mathrm{Cr})$ and copper $(\mathrm{Cu})$ using the MEMS technique (Process 1). The microchannel was fabricated using polymers (Process 2). The thermopiles were embedded into a silicon wafer using conventional wet chemical etching technique and photolithography. Four photomasks were prepared to make the $\mathrm{Cr}$ and $\mathrm{Cu}$ electrodes and also the SU-8 and PDMS microchannels.

\section{Process 1}

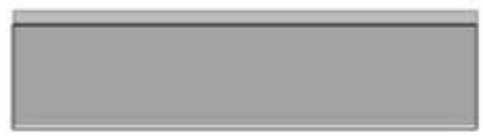

(a) Oxidation of Si wafer

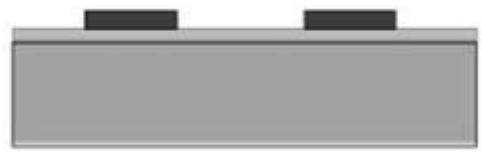

(b) Cr metal deposition and patterning

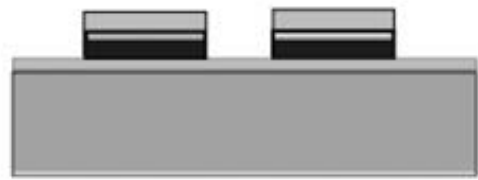

(c) Cu metal deposition and patterning

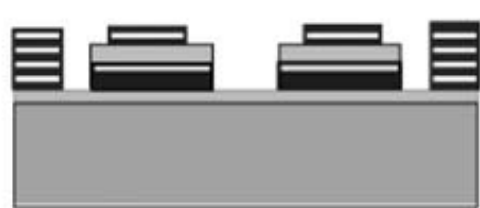

(d) SU-8 deposition and patterning

\section{Process 2}

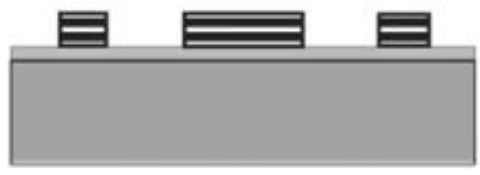

(e) SU-8 deposition and patterning

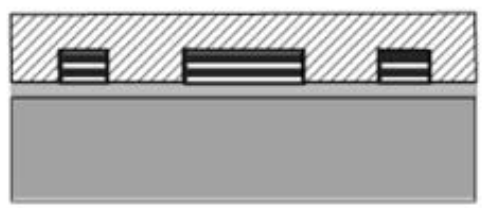

(f) PDMS molding and curing

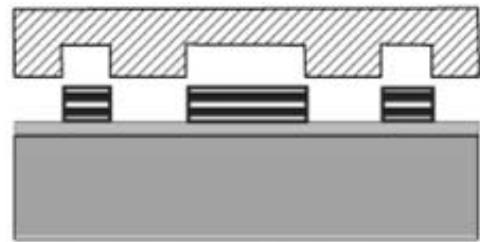

(g) Take apart PDMS molding

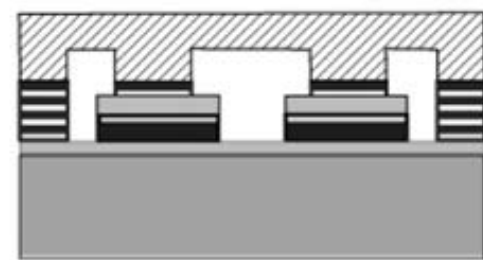

(h) PDMS aligning

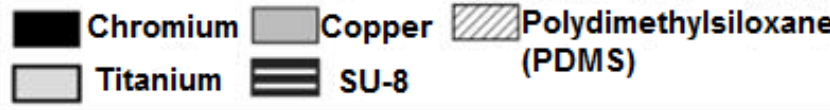

Figure 10: Fabrication of the dual thermopiles (Process 1) and microchannel (Process 2) [32] 
Wang et al. [15] introduced a MEMS thermal biosensor in Figure 11, specially designed for detecting heat release from enzymatic reactions from glucose or other metabolite solutions. Enzymes were first immobilized on the microbeads packed in the reaction chambers before the glucose solution was flowed into the chamber. The calorimeter was integrated with polymer-based microfluidic channels. The reaction chambers were based on free-standing polymer diaphragms with low thermal conductivity and surrounded with air gaps incorporated in the microfluidic system. The design helped to increase the thermal isolation and reduced the thermal mass of the chambers.

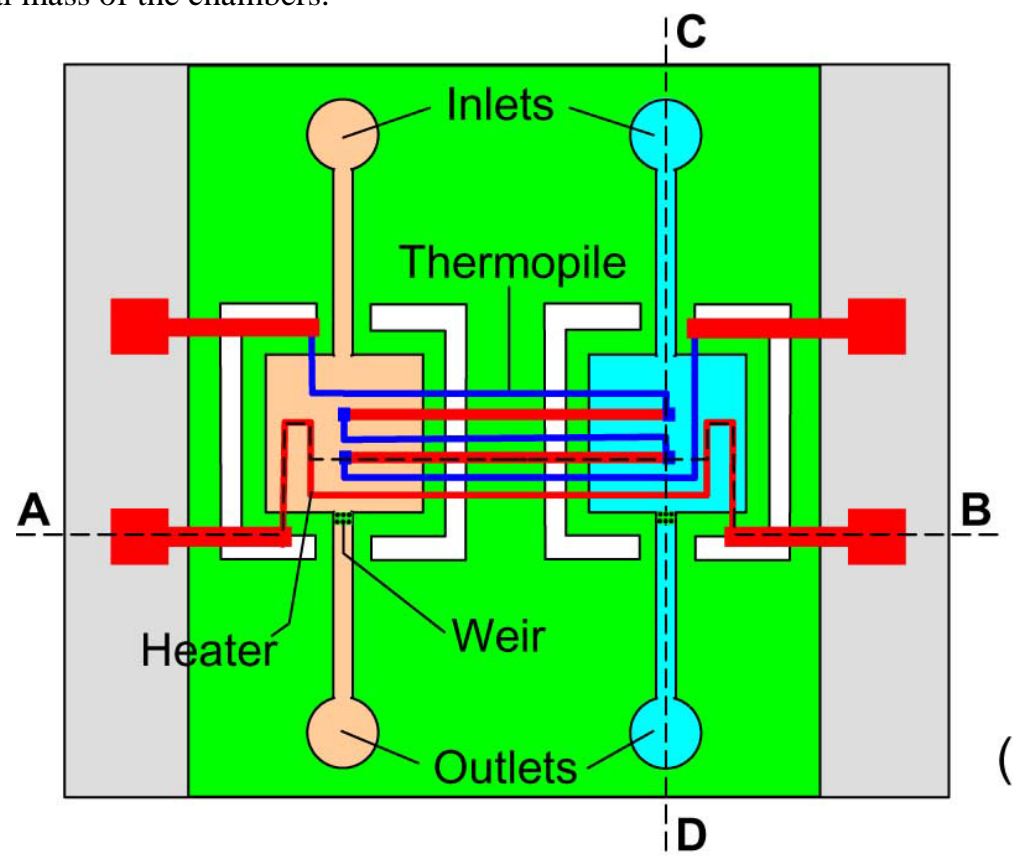

(b)

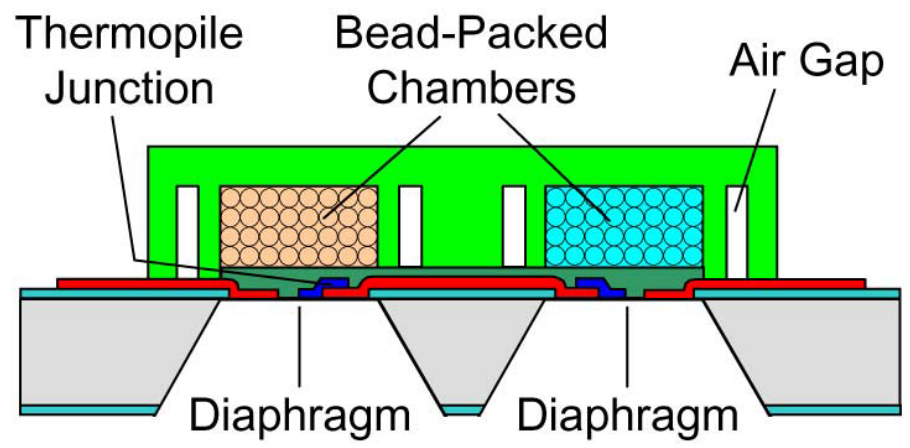

(a)

$A-B$

Figure 11: MEMS thermal biosensor: (a) top view as defined by the line A-B (b) Cross-section [15]

$\mathrm{Xu}$ et. al [9] presented a system for delivering sub-nL droplets of chemical reactants while avoiding evaporation via two layers of thermal shielding. The authors modified a commercial, suspended-membrane, thin film thermopile infrared sensor to integrate it into their microcalorimeter. A $50 \mathrm{~nL}$ droplet was initially placed directly on the sensor followed by a second droplet through a micropipette by means of a pressure driven droplet injector. The thermal shieldings were designed as follows. A Cu tube acted as an outer shield for a good electrical and convection shielding. A glass cover slide acted as an inner shield to protect the 
sensor from the external thermal noise. Sample evaporation was avoided by positioning the micropipette through a tiny hole in a cover glass, which was sealed with a drop of oil. Surface tension prevented the oil from leaking into the reaction chamber.

Lee et al. [11] developed a closed-chamber microcalorimeter as shown in Figure 12, with high sensitivity and accurate sample handling capabilities. Excellent thermal insulation was obtained by fabricating an onchip vacuum encapsulation. This work also combined the use of PDMS and parylene-C. Parylene-C was used to build the measurement and vacuum chambers. The flexible PDMS was used to form the microfluidic valves and pumps and was interfaced with the parylene-C channels and chambers to allow for an injection of samples of less than $1 \mathrm{~nL}$. The chip was capable of characterising the heat reaction of the hydrolysis of urea, as well as the enthalpy of a mixture of water with methanol.

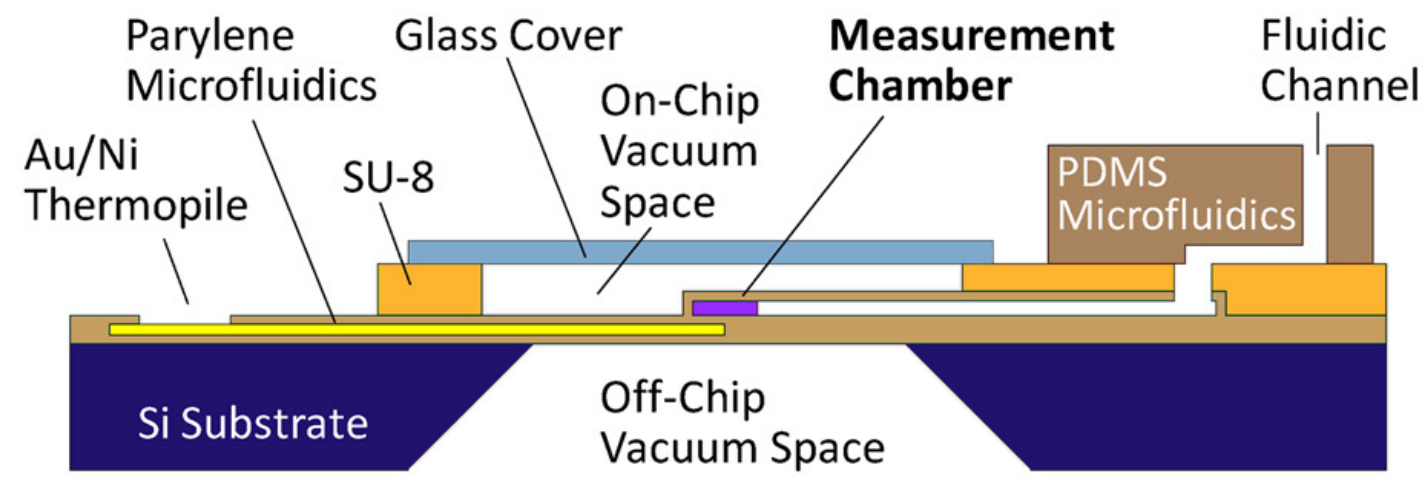

Figure 12: On-chip vacuum encapsulation calorimeter [11]

In a more recent work, Davaji et al. [16] constructed a microcalorimeter with a closed reaction chamber. The reaction chamber was 3D-micromachined using an anisotropic wet chemical etching process. This fabrication method eliminated the off-chip wafer bonding processes by direct integration of the thermal heater and temperature sensor onto the reaction chamber, as shown in Figure 13. The silicon nitride membrane was used to build the reaction chamber, and the chamber was suspended by the narrow tethers. This membrane reduced the thermal mass and increased the sensitivity of the system. Each microcalorimeter had two identical chambers for differential measurements. Samples were transferred via two microfluidic inlets. The heater and temperature sensor were on the opposite sides of the reaction chamber. This configuration allowed efficient coupling and detection of heat from the thermal elements. The prototype measured thermal diffusivity and specific heat of liquid samples. Other analysis can be carried out on the device without reconfiguration such as differential scanning calorimetry (DSC) [22-25], thermal wave analysis (TWA) [52,53], 3- $\omega$ technique [54] and titration $[8,18]$. 


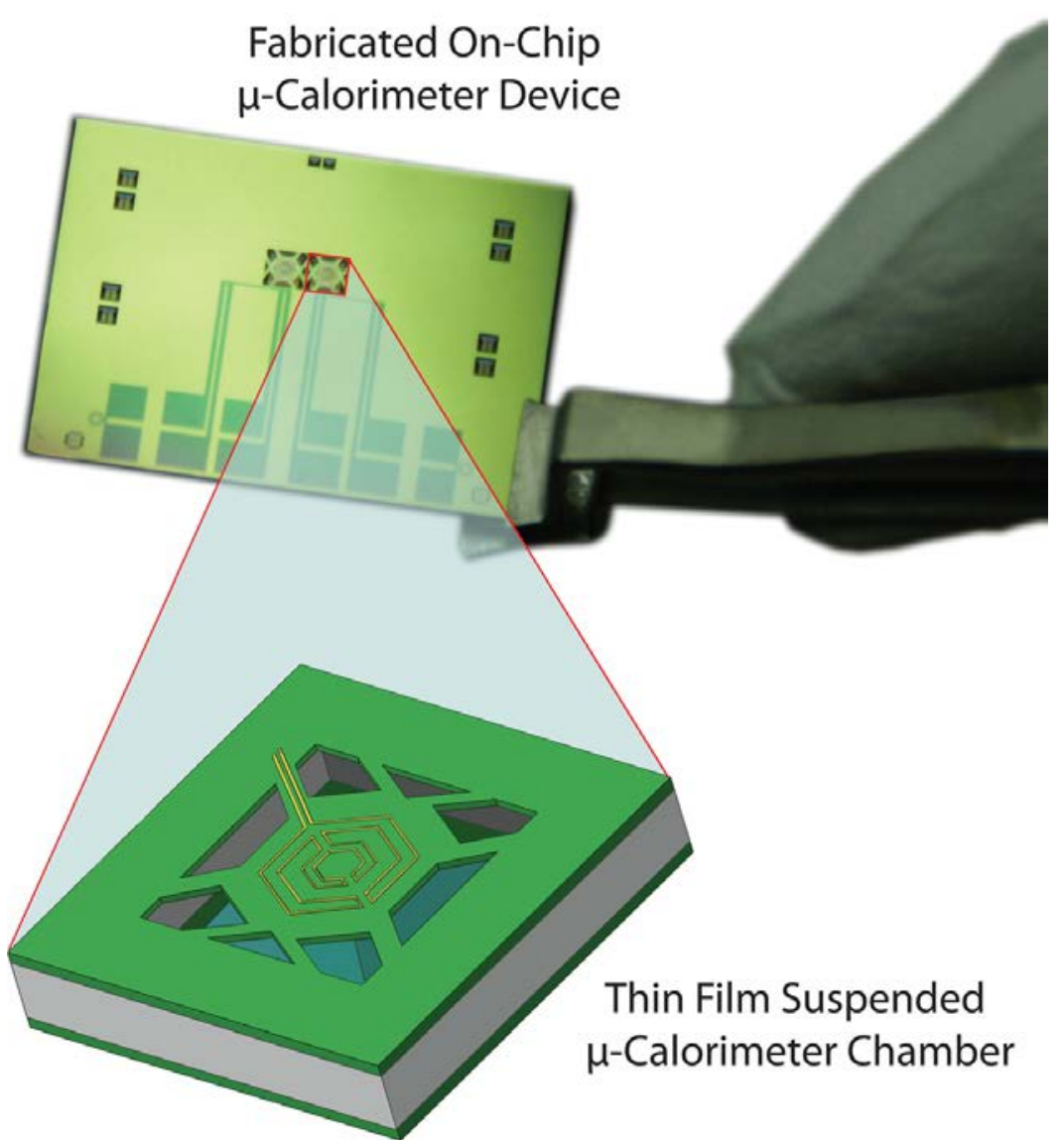

Figure 13: A 3D microcalorimeter with suspended reaction chamber [16]

Davaji et al. [16] also developed a metal patterning process to place the temperature sensors and heaters on the 3D structures of the SiN chamber. The process started with the symmetrical embossing of serpentine grooves on both sides of the wafer using a double-sided mask aligner. Then, the SiN and silicon dioxide $\left(\mathrm{SiO}_{2}\right)$ layers were etched by reaction ion etching (RIE) and buffered oxide etching (BOE) isotropic wet etching, respectively. The exposed silicon was then undercut using the poly etch. Subsequently, a SiN film was deposited to protect the exposed silicon via low pressure chemical vapour deposition (LPCVD).

Figure 14 shows the process flow for the 3D microfabrication of the microcalorimeter. Figure 14(a) shows the electrode patterns (heater and sensor) that were already printed symmetrically on both sides of the wafer as described in the previous process. Then the first anisotropic wet chemical $(\mathrm{KOH})$ etching (figure 14(b)) was performed on the bottom surface of the wafer to create the reaction chambers. In Figure 14(c), a second $\mathrm{KOH}$ etching was then applied to define the suspended tethers of SiN on the top surface. Lastly, the sensor and heater components were integrated on the device by a blanket deposition of nickel on both sides of the wafer. After metallization, a polyimide film was use to seal the bottom of the wafer to form fully enclosed reaction chamber. 
(a)
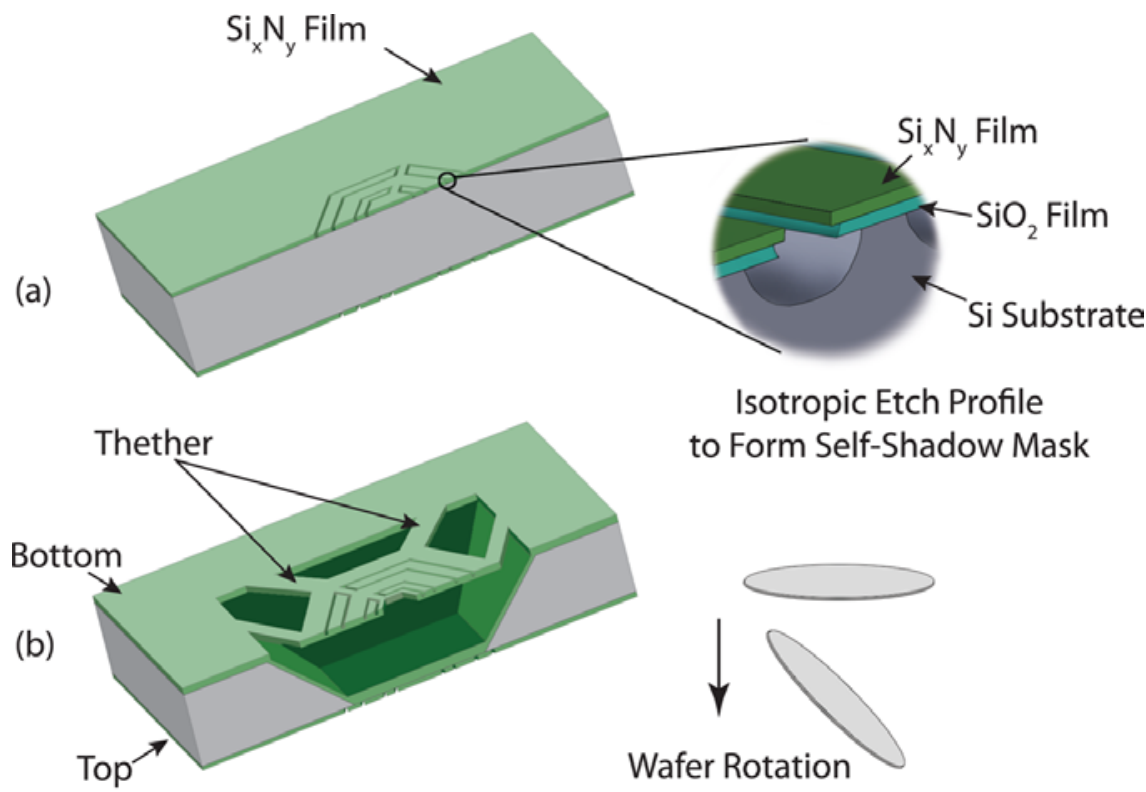

$$
\begin{gathered}
\text { Isotropic Etch Profile } \\
\text { to Form Self-Shadow Mask }
\end{gathered}
$$

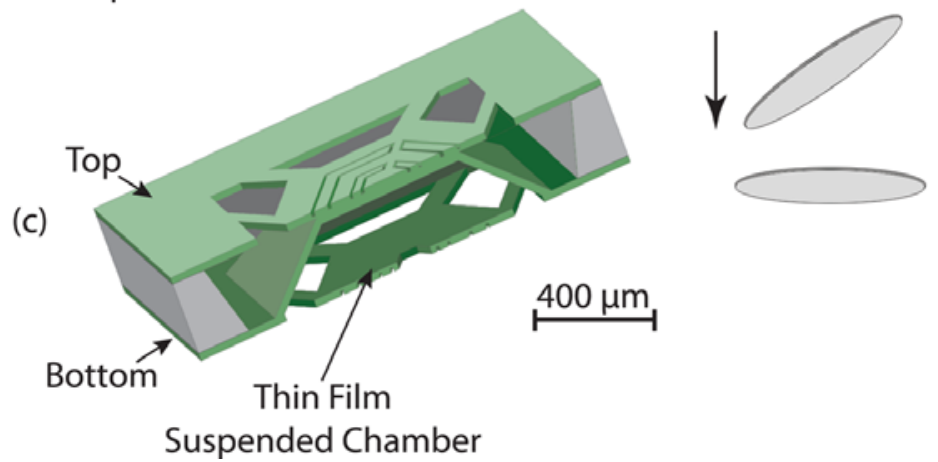

Figure 14: The process flow for 3D microfabrication of the calorimeter device [16]

Tables 3 and 4 summarize the previous works on the microcalorimeter. Table 3 compares the works in term of the type of chamber, fluid handling mechanisms, types of fluid-on-test, output resolution and power sensitivity. Table 4 compares these works in term of membrane material, temperature sensing, fluid handling material and the design novelty. 
Table 3: Comparison of works in the literature on the types of chamber and fluid handling with their results. [11]

\begin{tabular}{|c|c|c|c|c|c|c|c|c|}
\hline \multirow[t]{2}{*}{ Source } & \multicolumn{2}{|c|}{ Reaction chamber } & \multirow[t]{2}{*}{ Fluid handling } & \multirow[t]{2}{*}{ Fluid on test } & \multirow{2}{*}{$\begin{array}{c}\text { Thermal } \\
\text { conduct- } \\
\text { ance, } \mu \mathrm{W} / \mathrm{K}\end{array}$} & \multicolumn{2}{|c|}{ Resolution } & \multirow{2}{*}{$\begin{array}{c}\text { Power } \\
\text { sensitivity } \\
(\mathrm{V} / \mathrm{W})\end{array}$} \\
\hline & Type & Volume, $\mathrm{nL}$ & & & & $\begin{array}{l}\text { Power, } \\
\text { nW }\end{array}$ & $\begin{array}{l}\text { Practical } \\
\text { energy, } \mathrm{nJ}\end{array}$ & \\
\hline $\begin{array}{l}\text { Lee et. al } \\
\text { [11] }\end{array}$ & closed & 3.5 & $\begin{array}{c}\text { Multilevel } \\
\text { microfluidics }\end{array}$ & $\begin{array}{c}\text { Urea, Water } \\
\text { with } \\
\text { methanol } \\
\end{array}$ & 16 & 4.2 & 10 & NA \\
\hline $\begin{array}{l}\text { Zhang } \\
\text { et. al } \\
{[12]}\end{array}$ & closed & 15 & Syringe pump & $\begin{array}{c}\text { Glucose } \\
\text { oxidase, } \\
\text { catalase, } \\
\text { urease on } \\
\text { glucose, } \\
\text { hydrogen } \\
\text { peroxide and } \\
\text { urea }\end{array}$ & 5000 & 300 & $10^{5}$ & 0.94 \\
\hline $\begin{array}{l}\text { Baier et. } \\
\text { al [13] }\end{array}$ & closed & 6000 & Syringe pump & Enzyme & 10000 & 30 & 1000 & $4-6$ \\
\hline $\begin{array}{l}\text { Wang et. } \\
\text { al [15] }\end{array}$ & closed & 800 & Syringe pump & $\begin{array}{l}\text { Glucose } \\
\text { oxidase }\end{array}$ & 1500 & 50 & 5000 & $0.87-1.2$ \\
\hline $\begin{array}{l}\text { Davaji } \\
\text { et. al } \\
{[16]}\end{array}$ & closed & 200 & Microfluidics & $\begin{array}{c}\text { Water, } \\
\text { glycerol, } \\
\text { ionic liquids }\end{array}$ & NA & NA & NA & NA \\
\hline $\begin{array}{l}\text { Torres } \\
\text { et. al [5] }\end{array}$ & open & 500 & $\begin{array}{c}\text { Electrostatic } \\
\text { merging }\end{array}$ & $\begin{array}{c}\text { Protein } \\
\text { ligand } \\
\text { binding } \\
\text { interaction } \\
\end{array}$ & 1000 & 50 & 750 & NA \\
\hline $\begin{array}{l}\text { Recht et. } \\
\text { al [6] }\end{array}$ & open & 500 & $\begin{array}{c}\text { Electrostatic } \\
\text { merging }\end{array}$ & $\begin{array}{l}\text { Protein, } \\
\text { Enzyme } \\
\end{array}$ & 1000 & 50 & 750 & NA \\
\hline $\begin{array}{l}\text { Johan- } \\
\text { nessen } \\
\text { et. al[7] }\end{array}$ & open & 0.75 & Micropipette & $\begin{array}{c}\text { Reagents, } \\
\text { brown } \\
\text { adipocytes,ca } \\
\text { rdiomyocytes, } \\
\text { mitochondria }\end{array}$ & 100 & 13 & 100 & NA \\
\hline $\begin{array}{l}\text { Lerchner } \\
\text { et. al[8] }\end{array}$ & open & 6000 & Micropipette & $\begin{array}{c}\text { Enzyme } \\
\text { catalysed } \\
\text { reactions } \\
\text { (urea and } \\
\text { glucose) } \\
\end{array}$ & 30000 & 50 & 5000 & NA \\
\hline $\begin{array}{l}\text { Xu et. al } \\
\text { [9] }\end{array}$ & open & $5-50$ & Micropipette & Protein & 170 & 22 & 132 & $2.90(4)$ \\
\hline $\begin{array}{l}\text { Chancell } \\
\text { or et. al } \\
{[10]}\end{array}$ & open & 0.05 & Inkjet & $\begin{array}{c}\text { Enthalpies in } \\
\text { chemical or } \\
\text { biological } \\
\text { reaction }\end{array}$ & 90 & 150 & 500 & 6.34 \\
\hline $\begin{array}{l}\text { Kwak et. } \\
\text { al [17] }\end{array}$ & Closed & 70000 & $\begin{array}{c}\text { Microfluidic } \\
\text { channel }\end{array}$ & $\begin{array}{l}\text { Enzyme- } \\
\text { substrate } \\
\text { reaction }\end{array}$ & - & - & - & - \\
\hline
\end{tabular}


Table 4: Comparison of works in the literature on the types of material used in the production of the membrane, thermometry, microfluidics and the distinctiveness of the works.

\begin{tabular}{|c|c|c|c|c|c|}
\hline \multirow[t]{2}{*}{ Source } & \multirow{2}{*}{$\begin{array}{l}\text { Membrane } \\
\text { Material }\end{array}$} & \multicolumn{2}{|c|}{ Thermometry } & \multirow{2}{*}{$\begin{array}{l}\text { Microfluidics } \\
\text { material }\end{array}$} & \multirow[t]{2}{*}{ Novelties } \\
\hline & & Type & Material & & \\
\hline $\begin{array}{lll}\text { Lee et. al } \\
{[11]}\end{array}$ & Parylene-C & Thermopile & $\mathrm{Au} / \mathrm{Ni}$ & $\begin{array}{l}\text { PDMS and } \\
\text { parylene }\end{array}$ & $\begin{array}{l}\text { Combination of parylene-C and PDMS } \\
\text { microfluidics, on-chip vacuum } \\
\text { encapsulation, thermopile has a } \\
\text { meandering shape to increase its } \\
\text { longitudinal thermal resistance. Five } \\
\text { Au/Ni thermocouple junctions that are } \\
\text { connected in series to produce a total } \\
\text { Seebeck coefficient of } 110 \mu \mathrm{V} / \mathrm{K} \text {. }\end{array}$ \\
\hline $\begin{array}{l}\text { Zhang et. al } \\
\text { [12] }\end{array}$ & $\begin{array}{l}\mathrm{Si}_{3} \mathrm{~N}_{4}-\mathrm{SiO}_{2-} \\
\mathrm{Si}_{3} \mathrm{~N}_{4} \\
\end{array}$ & Thermopile & $\begin{array}{l}\text { gold }(\mathrm{Cr} / \mathrm{Au}) \text { on } \\
\text { p-type polysilicon }\end{array}$ & $\begin{array}{l}\text { Pyrex } 7740 \text { or } \\
\text { PDMS } \\
\end{array}$ & $\begin{array}{l}\text { Pyrex wafer is anodically bonded on } \\
\text { the polysilicon layer }\end{array}$ \\
\hline $\begin{array}{l}\text { Baier et. al } \\
\text { [13] }\end{array}$ & SU-8 on $\mathrm{Si}$ & Thermopile & $\begin{array}{l}\text { Thin film } \\
\text { BiSb/Sb }\end{array}$ & PMMA & $\begin{array}{l}\text { Based on SU-8 technology. Each } \\
\text { system consists of } 118 \text { thermocouples. }\end{array}$ \\
\hline $\begin{array}{l}\text { Wang et. al } \\
\text { [15] }\end{array}$ & SU-8 on $\mathrm{Si}$ & Thermopile & $\mathrm{Cr} / \mathrm{Ni}$ & PDMS & $\begin{array}{l}\text { Reaction chamber is filled with } \\
\text { microbeads to immobilize the enzymes } \\
\text { that react with the glucose fluids. The } \\
\text { chambers are on a freestanding SU-8 } \\
\text { polymer diaphragm base. Air gaps to } \\
\text { increase thermal isolation. }\end{array}$ \\
\hline $\begin{array}{l}\text { Davaji et. al } \\
\text { [16] }\end{array}$ & Silicon nitride & $\begin{array}{l}\text { Integrated } \\
\text { resistive } \\
\text { temperature } \\
\text { detector } \\
\text { (RTD) }\end{array}$ & Nickel & NA & $\begin{array}{l}\text { Fabrication of 3D reaction chamber } \\
\text { with integrated heater and temperature } \\
\text { sensor. Can perform several } \\
\text { measurements including batch and } \\
\text { scanning calorimetry. }\end{array}$ \\
\hline $\begin{array}{l}\text { Torres et. al } \\
\text { [5] }\end{array}$ & Polyimide & Thermistor & $\begin{array}{c}\text { Amorphous } \\
\text { silicon }\end{array}$ & NA & $\begin{array}{l}\text { An enthalpy array with the } 96 \\
\text { microcalorimeter in parallel. }\end{array}$ \\
\hline $\begin{array}{l}\text { Recht et. al } \\
\text { [6] }\end{array}$ & $\begin{array}{l}\text { Polyethylene } \\
\text { naphthalate } \\
\text { (PEN) }\end{array}$ & Thermistor & $\begin{array}{l}\text { Vanadium oxide } \\
\left(\mathrm{VO}_{\mathrm{x}}\right)\end{array}$ & NA & $\begin{array}{l}\text { Improvement of [5] by replacing the } \\
\text { polymide membrane with PEN, and } \\
\text { using } \mathrm{VO}_{\mathrm{x}} \text { thermopile. }\end{array}$ \\
\hline $\begin{array}{l}\text { Johan- } \\
\text { nessen et. al } \\
\text { [7] }\end{array}$ & $\mathrm{SiN}$ & Thermopile & $\mathrm{Ni} / \mathrm{Au}$ & NA & $\begin{array}{l}\text { Temperature sensing consists of } 10 \\
\mathrm{Ni} / \mathrm{Au} \text { thermocouple junctions that are } \\
\text { connected in series to produce a total } \\
\text { Seeback coefficient of } 220 \mu \mathrm{V} / \mathrm{K} \text {. }\end{array}$ \\
\hline $\begin{array}{l}\text { Lerchner et. } \\
\text { al [8] }\end{array}$ & $\mathrm{Si}$ & Thermopile & Silicon & NA & Pure silicon-based microcalorimeter. \\
\hline Xu et. al [9] & $\mathrm{SiO}_{2} / \mathrm{Si}_{3} \mathrm{~N}_{4}$ & Thermopile & $\begin{array}{c}\text { Silicon } \\
\text { (commercial) }\end{array}$ & NA & Double thermal shielding system. \\
\hline $\begin{array}{l}\text { Chancellor } \\
\text { et. al [10] }\end{array}$ & SiN & Thermopile & $\mathrm{Ti} / \mathrm{Bi}$ & NA & $\begin{array}{l}\text { Temperature sensing consists of } 7 \\
\text { Ti/Bi thermocouple junctions that are } \\
\text { connected in a series to produce a total } \\
\text { Seeback coefficient of } 574 \mu \mathrm{V} / \mathrm{K} \text {. }\end{array}$ \\
\hline $\begin{array}{l}\text { Kwak et. al } \\
\text { [17] }\end{array}$ & $\mathrm{Si}$ & Thermopile & $\mathrm{Cr} / \mathrm{Cu}$ & PDMS & $\begin{array}{l}\text { Temperature sensing consists of } 26 \\
\mathrm{Cr} / \mathrm{Cu} \text { thermocouple junctions that are } \\
\text { connected in a series to produce } \\
\text { Seeback coefficient of } 519.2 \mu \mathrm{V} / \mathrm{K} \text {. }\end{array}$ \\
\hline
\end{tabular}




\section{Conclusion}

In this review article, we discussed design considerations, materials and selected past works for the microcalorimeter. In term of design consideration, several choices must be carefully considered, namely the type of reaction chamber, thermal insulation, the fluid handling and the temperature measurement. As the volume of the fluid is going to the $\mathrm{nL}$ and $\mathrm{pL}$ regions, the trend is towards the microfluidic-based activemixing system with an enclosed chamber to reduce thermal dissipation and hence increased accuracy. In term of making the membrane, Silicon and $\mathrm{SiN}$ are the de facto materials because of their higher thermal conductivity. However, polymers such as parylene and SU-8 are the emerging candidates in the closedchamber configuration due to their higher thermal insulations. Thermopile instead of thermistor is the preferred choice to measure the temperature due to its higher sensitivities. In the fluid handling and mixing, PDMS instead of PMMA is the dominant material due to its greater degree of deformation. Finally, we reviewed the past works. Table 3 and 4 summarise our findings. We notice the unified trend in all of these microcalorimeter prototypes i.e. the higher level of integration of design techniques, materials and fabrication processes to produce microcalorimeters with higher accuracies, while consuming small inputs (biological samples).

\section{Acknowledgements}

This work is supported by Queensland Micro- and Nanotechnology Centre (QMNC) and Griffith School of Engineering. This work was performed in part at the Queensland node of the Australian National Fabrication Facility, a company established under the National Collaborative Research Infrastructure Strategy to provide nano and microfabrication facilities for Australia's researchers.

\section{References}

[1] J. Voldman, M.L. Gray, M.A. Schmidt, Annual review of biomedical engineering 1 (1999) 401.

[2] L.J. Lee W, Koh J, Nanobiosensors in Disease Diagnosis 2012:1 (2012) 17.

[3] M.W. Freyer, E.A. Lewis, Method Cell Biol 84 (2008) 79.

[4] T. Maskow, H. Harms, Engineering in Life Sciences 6 (2006) 266.

[5] F.E. Torres, P. Kuhn, D. De Bruyker, A.G. Bell, M.V. Wolkin, E. Peeters, J.R. Williamson, G.B. Anderson, G.P. Schmitz, M.I. Recht, S. Schweizer, L.G. Scott, J.H. Ho, S.A. Elrod, P.G. Schultz, R.A. Lerner, R.H. Bruce, Proc Natl Acad Sci U S A 101 (2004) 9517.

[6] M.I. Recht, D. De Bruyker, A.G. Bell, M.V. Wolkin, E. Peeters, G.B. Anderson, A.R. Kolatkar, M.W. Bern, P. Kuhn, R.H. Bruce, F.E. Torres, Anal. Biochem. 377 (2008) 33.

[7] E.A. Johannessen, J.M. Weaver, L. Bourova, P. Svoboda, P.H. Cobbold, J.M. Cooper, Analytical chemistry 74 (2002) 2190.

[8] J. Lerchner, A. Wolf, G. Wolf, Journal of thermal analysis and calorimetry 57 (1999) 241.

[9] J. Xu, R. Reiserer, J. Tellinghuisen, J.P. Wikswo, F.J. Baudenbacher, Analytical chemistry 80 (2008) 2728.

[10] E. Chancellor, J. Wikswo, F. Baudenbacher, M. Radparvar, D. Osterman, Applied physics letters 85 (2004) 2408.

[11] W. Lee, W. Fon, B.W. Axelrod, M.L. Roukes, Proceedings of the National Academy of Sciences 
(2009).

[12] Y. Zhang, S. Tadigadapa, Biosensors and Bioelectronics 19 (2004) 1733.

[13] V. Baier, R. Födisch, A. Ihring, E. Kessler, J. Lerchner, G. Wolf, J. Köhler, M. Nietzsch, M. Krügel, Sensors and Actuators A: Physical 123 (2005) 354.

[14] M. Zieren, R. Willnauer, J. Köhler, Flow-through chip calorimeter based on BiSb/Sb-thin-film thermopiles with a thermopower of $64 \mathrm{mV} / \mathrm{K}$, Micro Total Analysis Systems 2000. Springer, 2000, p. 71.

[15] L. Wang, D.M. Sipe, Y. Xu, Q. Lin, Microelectromechanical Systems, Journal of 17 (2008) 318.

[16] B. Davaji, H.J. Bak, W.-J. Chang, C.H. Lee, Biomicrofluidics 8 (2014) 034101.

[17] B.-S. Kwak, B.-S. Kim, H.-H. Cho, J.-S. Park, H.-I. Jung, Dual Micro-Thermopile Based Biocalorimeter for Enzyme-Substrate Reaction, Sensors, 2007 IEEE. IEEE, 2007, p. 740.

[18] H. Huth, A. Minakov, C. Schick, Journal of Polymer Science Part B: Polymer Physics 44 (2006) 2996.

[19] G. Höhne, W. Hemminger, H.-J. Flammersheim, Differential scanning calorimetry, Springer, 2003.

[20] P. Gill, T.T. Moghadam, B. Ranjbar, Journal of biomolecular techniques: JBT 21 (2010) 167.

[21] H. Esfandyarpour, R. Davis, An Integrated Differential Nanocalimeter with On-Chip Microfluidic Multiplexing for High Throughput Genomics and Proteomics, 14th Int'l Conf. on Miniaturized Systems for Chem. And Life Sciences, p. 3.

[22] E. Zhuravlev, C. Schick, Thermochimica Acta 505 (2010) 1.

[23] T. Roy, A. Sinha, S. Chakraborty, R. Ganguly, I.K. Puri, Phys. Fluids. 21 (2009) 027101.

[24] Z. Long, A.M. Shetty, M.J. Solomon, R.G. Larson, Lab. Chip. 9 (2009) 1567.

[25] D. De Bruyker, M.I. Recht, A.A.S. Bhagat, F.E. Torres, A.G. Bell, R.H. Bruce, Lab. Chip. 11 (2011) 3313.

[26] L.-H. Lu, K.S. Ryu, C. Liu, Microelectromechanical Systems, Journal of 11 (2002) 462.

[27] B. Xie, M. Mecklenburg, B. Danielsson, O. Öhman, P. Norlin, F. Winquist, Analyst 120 (1995) 155.

[28] J. Lerchner, A. Wolf, G. Wolf, V. Baier, E. Kessler, M. Nietzsche, M. Krugel, Thermochimica Acta 445 (2006) 144.

[29] L.M. Ahmad, B. Towe, A. Wolf, F. Mertens, J. Lerchner, Sensor Actuat B-Chem 145 (2010) 239.

[30] J. Lerchner, T. Maskow, G. Wolf, Chemical Engineering and Processing: Process Intensification 47 (2008) 991.

[31] L. Wang, B. Wang, Q. Lin, Sensors and Actuators B: Chemical 134 (2008) 953.

[32] B. Kwak, B. Kim, H. Cho, J. Park, H. Jung, Microfluidics and Nanofluidics 5 (2008) 255.

[33] K. Verhaegen, K. Baert, J. Simaels, W. Van Driessche, Sensors and Actuators A: Physical 82 (2000) 186.

[34] C. Liu, Advanced Materials 19 (2007) 3783.

[35] G. Voskerician, M.S. Shive, R.S. Shawgo, H.v. Recum, J.M. Anderson, M.J. Cima, R. Langer, Biomaterials 24 (2003) 1959.

[36] A. Neumann, T. Reske, M. Held, K. Jahnke, C. Ragoss, H. Maier, Journal of Materials Science: Materials in Medicine 15 (2004) 1135.

[37] N.-T. Nguyen, BioMEMS and Biomedical Nanotechnology, Springer, 2007, p. 93.

[38] J.R. Dorvee, A.M. Derfus, S.N. Bhatia, M.J. Sailor, Nat Mater 3 (2004) 896.

[39] A. Del Campo, C. Greiner, Journal of Micromechanics and Microengineering 17 (2007) R81.

[40] S.K. Mitra, S. Chakraborty, Microfluidics and Nanofluidics Handbook: fabrication, implementation, and applications, CRC Press, 2011.

[41] T.-Q. Truong, N.-T. Nguyen, International Journal of Computational Engineering Science 4 (2003) 667.

[42] H.-S. Noha, Y. Huangb, P.J. Hesketha, Sensors and Actuators B: Chemical 102 (2004) 78.

[43] M.C. Bélanger, Y. Marois, Journal of biomedical materials research 58 (2001) 467. 
[44] H. Bourbaba, B. Mohamed, Energy Procedia 36 (2013) 231.

[45] H. Lorenz, M. Despont, N. Fahrni, N. LaBianca, P. Renaud, P. Vettiger, Journal of Micromechanics and Microengineering 7 (1997) 121.

[46] P. Abgrall, V. Conedera, H. Camon, A.M. Gue, N.T. Nguyen, Electrophoresis 28 (2007) 4539.

[47] F.E. Torres, M.I. Recht, J.E. Coyle, R.H. Bruce, G. Williams, Curr Opin Struc Biol 20 (2010) 598.

[48] D. De Bruyker, M. Wolkin, M. Recht, F. Torres, A. Bell, G. Anderson, E. Peeters, A. Kolatkar, P. Kuhn, R. Bruce, MEMS-based enthalpy arrays, Solid-State Sensors, Actuators and Microsystems Conference, 2007. TRANSDUCERS 2007. International. IEEE, 2007, p. 1757.

[49] T. Instruments.

[50] D. De Bruyker, M. Recht, F.E. Torres, A.G. Bell, R.H. Bruce, Vanadium oxide thermal microprobes for nanocalorimetry, Sensors, 2010 IEEE. IEEE, 2010, p. 2358.

[51] A. Van Herwaarden, P. Sarro, Sensors and Actuators 10 (1986) 321.

[52] T. Hashimoto, J. Morikawa, T. Kurihara, T. Tsuji, Thermochimica acta 304 (1997) 151.

[53] J. Morikawa, C. Leong, T. Hashimoto, T. Ogawa, Y. Urata, S. Wada, M. Higuchi, J.-i. Takahashi, Journal of Applied Physics 103 (2008) 063522.

[54] D.G. Cahill, Review of Scientific Instruments 61 (1990) 802. 